\title{
(C) OPEN ACCESS \\ Virtual reality videos used in undergraduate palliative and oncology medical teaching: results of a pilot study
}

\author{
Mark Taubert, ${ }^{\oplus 1,2}$ Lucie Webber, ${ }^{2}$ Timothy Hamilton, $^{3}$ Madeleine Carr, ${ }^{4}$ \\ Mark Harvey ${ }^{5}$
}

\section{Correspondence to} Dr Mark Taubert, Palliative Medicine, Velindre NHS Trust, CardiffCF14 2TL, UK; mtaubert@doctors.org.uk

Received 12 November 2018 Revised 9 January 2019 Accepted 23 January 2019 Published Online First

26 February 2019

\begin{abstract}
${ }^{1}$ Palliative Medicine, Velindre NHS Trust, Cardiff, UK

${ }^{2}$ Cardiff University School of Medicine, Cardiff, UK

${ }^{3}$ Palliative Medicine, Velindre Cancer Centre, Cardiff, UK

${ }^{4}$ Marie Curie Hospice Cardiff and Vale, Cardiff, UK

${ }^{5}$ Media and Technology, Velindre Cancer Centre, Cardiff, UK
\end{abstract}

\section{(D) Check for updates}

(C) Author(s) (or their employer(s)) 2019. Re-use permitted under CC BY-NC. No commercial re-use. See rights and permissions. Published by BMJ.

To cite: Taubert $\mathrm{M}$, Webber $\mathrm{L}$, Hamilton T, et al. BMJ

Supportive \& Palliative Care 2019:9:281-285

\begin{abstract}
Background Virtual reality (VR) immersive environments have been shown to be effective in medical teaching. Our university hospital received funding from our deanery, Health Education in Wales, to film teaching videos with a 360-degree camera.
\end{abstract}

Aims To evaluate whether VR is an effective and acceptable teaching environment. VR headsets were set up for medical students who rotated through Velindre Cancer Hospital's Palliative Care department.

Methods Students were asked to put on a VR headset and experience a pre-recorded 27 min presentation on nausea and vomiting in palliative care settings. They subsequently viewed a radiotherapy treatment experience from a patient's point of view.

Results Of the 72 medical students who participated, 70 found the experience comfortable, with two students stating they felt the experience uncomfortable ( 1 =headset too tight; 1 =blurry visuals). Numerical scoring on ability to concentrate in VR from 0 to 10 ( $0=$ worst, $10=$ best) scored an average of 8.44 (range, 7-10). Asked whether this format suited their learning style, average score was 8.31 (range $6-10) .97 .2 \%(n=70)$ students stated that they would recommend this form of learning to a colleague, with one student saying he/she would not recommend and another stating he/she was unsure. Students left anonymous free-text feedback comments which helped frame future needs in this emerging area.

Discussion This study suggests that there is room for exploring new ways of delivering teaching and expanding it more widely in palliative care and oncology, but also provides feedback on areas that need further careful attention. Comments from students included: "Might have been the novelty factor but I learnt more from this 20 min VR thing than I have from many lectures".

Summary The project has proved sufficiently popular in medical student feedback, that the VR experience is now available on YouTube and has been permanently introduced into routine teaching. Further 360-degree teaching environments have been filmed. Of note is that our 360-degree videos have been viewed in Africa, so this format of teaching could prove valuable due to its global reach.

\section{INTRODUCTION}

Virtual reality (VR) is an exciting technologically advanced system that allows users to experience a 'virtual world'. The potential applications for VR in medical education are vast and recent advances in technology and improved accessibility have made it the exciting and emerging field it is today. ${ }^{1}$

VR has been widely adopted and accepted as a valid tool for training practical skills and procedures across a number of medical and surgical specialties such as laparoscopy ${ }^{23}$ and gastrointestinal endoscopy training ${ }^{4}$ to name a few. Samadbeik et $\mathrm{al}^{5}$ conducted a scoping review study in 2016 aiming to identify the applications of VR technology for training across a range of medical groups and demonstrated that $95 \%$ of the studies included emphasised the improvement of the skills of trainees when using VR.

Its application in undergraduate training as a supplement for traditional lectures, tutorials and self-directed learning appears less well studied; however, there is evidence that VR has been shown to increase knowledge retention and study motivation. ${ }^{6}$ Arguably, it may in future 
also prove a more realistic simulated environment to use when students have missed lectures or tutorials, for instance due to ill health, so a comparison with a more standard video of a lecture or tutorial is warranted. ${ }^{7}$

The purpose of this study was to evaluate the views of undergraduate medical students experiencing a 27 min VR lecture on nausea and vomiting management in palliative care and oncology settings, and a VR experience of radiotherapy from a patient's point of view.

\section{BACKGROUND}

VR can be described as a computer-generated environment which can be explored and interacted with by a person.

To achieve this, VR uses a range of technologies to stimulate our senses and create an illusion of reality, where the person feels as though they are actually present in that environment.

VR headsets create 360-degree cinematic images that can change in real time as the person moves around the environment. If a user looks in front, up, down or behind them, they will see what the entire environment picked up by the 360-degree camera has picked up. Combined with headphones and additional VR equipment that allows for tactile and haptic feedback such as gloves, this can contribute to an immersive experience and thus make the VR experience distinct from merely watching media on a flat two-dimensional screen. VR is distinctive from augmented reality (AR) and mixed reality in the immersive reality field, and the latter have not been used for the purpose of this study.

Uses in palliative care settings have included improvements in patient experience in settings such as hospices, and are being rolled out to include personalised virtual reality therapy to help with anxiety and distress. ${ }^{8}$ A podcast on the huge potential of this technology to patients, healthcare professionals and learners in palliative care settings describes novel uses in end-of-life care settings. ${ }^{9}$

In 2017 and 2018, a VR library was created in a teaching hospital in Cardiff. A teaching video was filmed with a 360-degree camera, to recreate a nausea and vomiting in palliative care tutorial in an immersive teaching room environment. A radiotherapy session from a patient's point of view was also filmed, to demonstrate to medical students what radiotherapy looks like. This was done on feedback from students that they often did not get a full opportunity to see what radiotherapy involves, even after having been on placement in the cancer centre. The cancer centre's radiotherapy suites are often very busy, so for logistical reasons not all students can experience this physically.

While wearing the headset, the students were able to move their point of view and look around the virtual room, and have the perception that they were actually in the audience of a live lecture (video $1^{10}$ ) or in the radiotherapy room itself (video $2^{11}$ ).
In the tutorial, Dr Taubert, consultant in palliative care, delivers a review of nausea and vomiting management in oncology and palliative care. He uses a slideshow presentation projected onto the wall behind him as an accompaniment to his tutorial. To translate this to the VR setting and ensure clarity of the font on the slides, it was necessary to superimpose the slideshow onto the footage after filming.

Filming with a 360-degree camera was a new experience for clinicians and our hospital's media development officer, and a blog on some of the mistakes and discoveries that were made in the process can be found on the BMJ Supportive \& Palliative Care journal blog. ${ }^{12}$ Technical expertise was provided by a local Welsh company, Orchard Media and Events Group (Orchard 360), who specialise in VR and AR, and they kindly provided their time and expertise for free.

\section{METHODS}

Two 360-degree videos were filmed and edited. They were then made ready to view in VR headsets, as described in the Background section. VR headsets were set up for medical students who rotated through Velindre Cancer Centre's Oncology and Palliative Care departments. Oculus Rift virtual reality headsets (2016 version) connected to laptops with appropriate graphic cards were used. Two videos were evaluated by 72 Cardiff University medical students over consecutive weeks of the academic year. Students were asked to put on a VR headset, and watch the 27 min video on nausea and vomiting management in palliative care and oncology settings. They were also able to view the Radiotherapy Patient view VR experience.

Students then completed a questionnaire. They were asked to grade their comfort, their ability to concentrate and asked if they felt the VR experience suited their own personal style. They were also asked whether they would recommend the experience to their peers. Users were also encouraged to leave free-text positive comments and constructive feedback.

The survey can be seen in box 1 .

Basic quantitative and descriptive analysis of the data was then carried out.

\section{RESULTS}

Of the 72 medical students who participated, 70 found the experience comfortable, with 2 students stating they felt the headset uncomfortable $(1=$ headset too tight, $1=$ visuals blurry). Numerical scoring on ability to concentrate in VR from 0 to $10(0=$ worst, $10=$ best $)$ scored an average of 8.44 (range, 7-10). The majority of students felt that this format suited their personal learning style, with an average score of 8.31 (range 6-10) reported. Moreover, 97.2\% $(n=70)$ students stated that they would recommend this form of learning to a colleague, with one student saying he/she would not recommend and one student stating he/she was unsure. 
Box 1 Survey on virtual reality tutorial Velindre Cancer Centre Palliative Care teaching for medical students using Oculus Rift

\section{Did you find the 360-degree VR experience comfortable? \\ Yes No}

On a scale from 0 to 10 (with 0 being not at all and 10 being maximum)

How able were you to concentrate on the content of the tutorial in Virtual Reality?

012345678910

Did this suit your own learning style? 012345678910

Would you recommend a VR tutorial like this one to a colleague if it were freely available on YouTube? Yes No Don't Know

\section{Any Comments?}

Students left free-text comments, which included constructive feedback. One student commented: "A totally immersive experience! I took it in as if I had actually been in the room..."

Another stated: "I learnt more from this 20 min VR thing, than I have from many lectures".

The positive comments were categorised into common themes:

1. Immersive.

2. Better than a normal video/lecture.

3. Easy to concentrate.

4. Engaging.

5. Good length.

Thirty-eight students in total volunteered positive feedback in the comments section (see figure 1), $34 \%$ of the comments suggested they found the VR tutorial to be a better format for learning than a standard lecture or video, and $24 \%$ and $21 \%$ of students commented that the video was immersive or engaging, respectively.

Thirty-six students left free-text feedback on issues that might make the VR experience better. These were also categorised into eight main common themes: (1) difficulties in taking notes, (2) image quality, (3) inability to pause/rewind, (4) length of the presentation, (5) difficulty with glasses, (6) inability to ask questions, (7) uncomfortable headset and (8) difficult to tolerate due to dizziness. The majority of feedback suggested finding a way to take notes or improve image quality, $33 \%$ and $25 \%$, respectively (see figure 2).

Examples of free-text comments:

"Very interesting and informative, really real! Interesting way to learn".

"Found it easier to concentrate than watching a standard video on a laptop. Was less easily distracted as felt like you were in the tutorial".

"Really interesting, a lot more immersive than YouTube videos so easier to concentrate on the content. 25 min was a good length. Thank you for the learning".

"Really good idea, not far off real life. Would become more effective the more it is used".

"It was great, thank you, and increased my concentration. Really helpful to see patient perspective".

"Was still able to take notes which is good although wasn't the easiest-would recommend and use.

"Very good. Thank you for a lovely experience. It was very well received".

"Suited my learning style, quite relaxing and able to concentrate. Couldn't look at my mobile phone which is a good thing!"

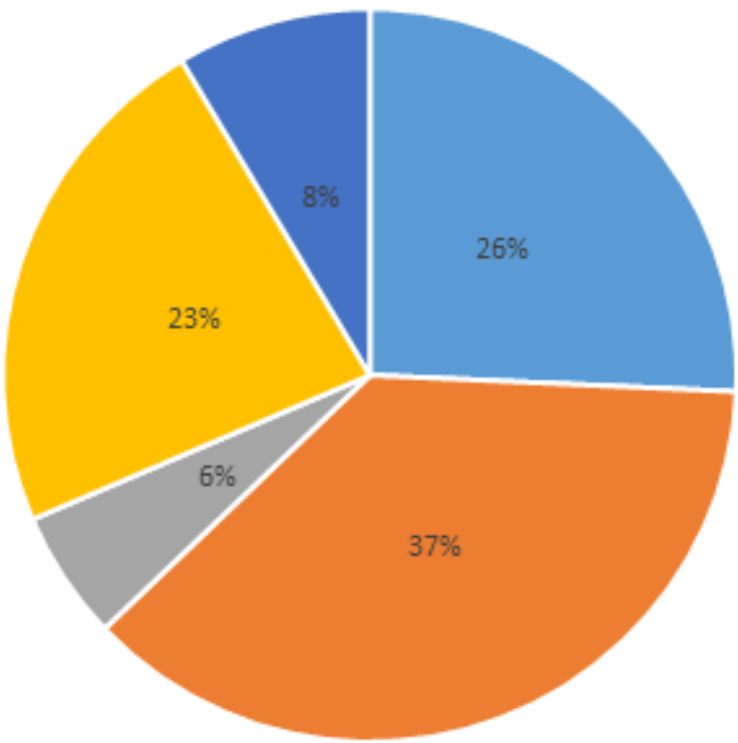

- Immersive

- Better than a normal video/lecture

- Easier to concentrate

- Engaging

- Good length

Figure 1 Positive feedback—grouped into 6 common themes. 


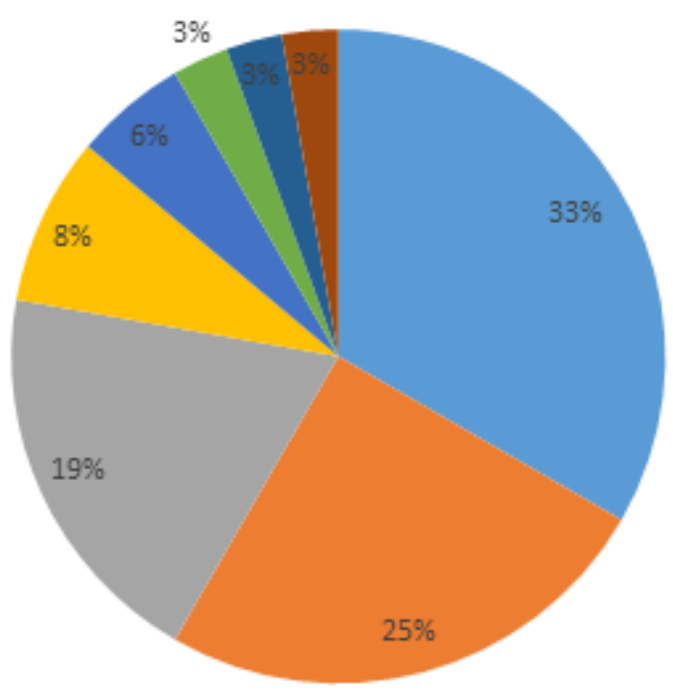

- unable to take notes

n Sub-optimal imagequality

- Would like to be able to pause \& rewind

n Longer would have been uncomfortable

- Difficuty with glasses

n Unable to åk questions

- Headset was uncomfortable

- Dizzy

Figure 2 Negative feeback—grouped into 8 common themes.

"Interesting way to learn, felt like being in real tutorial. Benefit of being able to access it at all times on YouTube for revision".

"Might have been the novelty factor but I learnt more from this $20 \mathrm{~min}$ VR thing than I have from many lectures. No escape in VR, you have to listen!”

"Difficult to take notes as I was unable to comfortably see the pen and paper, also I would usually take notes on a laptop which would be impossible. It would be helpful to be able to pause and rewind the tutorial".

"Non-engagement with the teacher (eg, being unable to ask questions)".

"Would be uncomfortable for longer lengths of time".

"A bit blurry (especially with glasses) and took some getting used to so I couldn't concentrate too much for the first 5 min".

"Analogue Reality where you can look at virtual and real life may help with taking notes, however then you also have more outside distractions".

Results and free-text comments were fed back to VR developers and companies with an interest in developing VR/AR environments for healthcare and education settings.

\section{CONCLUSION}

Feedback on this new teaching tool was positive with students rating it very highly and wanting to see more of it being used for the undergraduate taught course. Many commented that they found the experience more immersive than a routine video and found the immersive nature useful. They were enthusiastic about being able to view it again on YouTube for revision purposes where the option of watching it as a standard video or a 360-degree VR video is available. The YouTube video has attracted nearly 5000 views in a year, including international viewers from Africa. Students who were not able to attend the day at the cancer centre (for instance due to ill health) were subsequently able to experience the same tutorial that their peers had seen.

An unexpected outcome of this project was that students commented that this full immersion within a VR environment meant that there was a lack of 'outside world' distractions like mobile phones. On the other hand, there was some discussion on whether being fully immersed might make future students feel a bit vulnerable, especially within a busy library environment as they would not be able to see who was near them, when fully immersed in VR.

While it is possible to pause and rewind with all modern VR and AR equipment, the mechanisms for doing so are not always apparent for first time users. Most VR machines have a controller (or in our case two controllers) and some students found it easy to pause and rewind; however, those who did not needed further detailed instructions. The controllers for our Oculus Rift contained a total of 12 buttons, levers and triggers, and students did not always intuitively know how best to hold them, and which was the right and the left device. It would therefore seem advisable for industry to devise very simpler, more intuitive ways of interacting with VR, especially for newcomers, or for younger/elderly patients who might struggle with complex systems.

It was also noted that students still like the ability to take written notes when they are in a tutorial or learning environment, and based on this study we are contacting VR content providers on providing a simple solution to facilitate this in fully immersive VR. Blurriness in VR is more readily correctable with more recent VR devices, and those students who found the headsets too tight had been given instructions on how to loosen them with the Velcro strap, but had not done this during tutorial. 


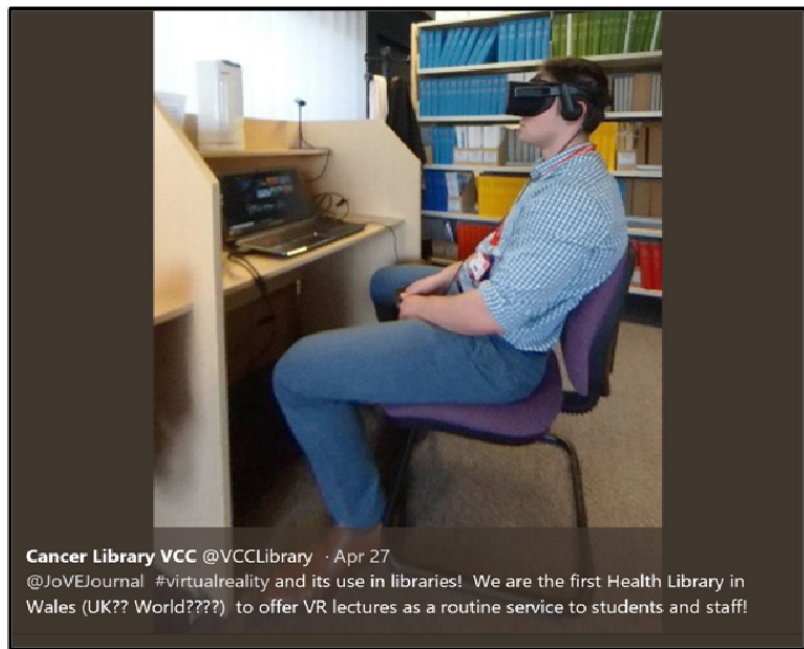

Figure 3 A tweet about routine use of Virtual Reality tutorials in Velindre Cancer Centre's Health Library, as set up by the project team. ${ }^{13}$

The primary purpose of this project was to evaluate the effectiveness of using VR as a teaching tool for medical students. The survey (box 1) was designed to get the students' feedback on this style of teaching compared with traditional lectures and seminars, and therefore focused mainly on the nausea and vomiting tutorial. While there was a free-text box to allow more general comments on the two experiences, not many students made reference specifically to the second video. It could be of interest to carry out future projects using similar patient perspective VR scenes (eg, chemotherapy, inpatient settings, clinics) and evaluating students' reactions to this. The two VR experiences were analysed by the students on the same feedback questionnaire and many of the students commented on the 27 min tutorial but fewer commented specifically on the patient experience of radiotherapy (one commented that it was 'helpful to see patient perspective').

Future project leads using with VR/AR may wish to take some of the above experiences into account. The hospital's cancer services university library now has two VR booths (see figure 3), and students and healthcare professionals access the material on a nearly daily basis. Further projects, with the right funding and industry expertise, will involve VR and AR for patient distraction during day case procedures. Also, further evaluation into how experiences like this might impact on medical students' empathy towards patients will be of value, as we move towards technology that can help with ever more real scenarios and simulation.

Contributors MT wrote the initial draft and LW, TH, MC and $\mathrm{MH}$ co-wrote and reviewed the document. All authors edited the paper until it was completed.

Funding Wales Deanery Medical Education Department (now Healthy Education in Wales-HEIW) gave MT a grant of $£ 3000$ to spend on Virtual Reality equipment for teaching purposes, after MT won a postgraduate teaching award.
Orchard Media gave their time and expertise for free to help with filming and give talks and technical advice.

Competing interests None declared.

Patient consent Not required.

Provenance and peer review Not commissioned; externally peer reviewed.

Open access This is an open access article distributed in accordance with the Creative Commons Attribution Non Commercial (CC BY-NC 4.0) license, which permits others to distribute, remix, adapt, build upon this work noncommercially, and license their derivative works on different terms, provided the original work is properly cited, appropriate credit is given, any changes made indicated, and the use is noncommercial. See: http://creativecommons.org/licenses/by-nc/4. $0 /$.

\section{REFERENCES}

1. Stepan K, Zeiger J, Hanchuk S, et al. Immersive virtual reality as a teaching tool for neuroanatomy. Int Forum Allergy Rhinol 2017;7:1006-13.

2. Gallagher AG, Seymour NE, Jordan-Black J-A, et al. Prospective, randomized assessment of transfer of training (TOT) and transfer effectiveness ratio (TER) of virtual reality simulation training for laparoscopic skill acquisition. Ann Surg 2013;257:1025-31.

3. Alaker M, Wynn GR, Arulampalam T. Virtual reality training in laparoscopic surgery: a systematic review $\&$ meta-analysis. Int J Surg 2016;29:85-94.

4. Khan R, Plahouras J, Johnston BC, et al. Virtual reality simulation training for health professions trainees in gastrointestinal endoscopy. Cochrane Database Syst Rev 2018;37. CD008237.

5. Samadbeik M, Yaaghobi D, Bastani P, et al. The applications of virtual reality technology in medical groups teaching. $J A d v$ Med Educ Prof 2018;6:123-9.

6. Ekstrand C, Jamal A, Nguyen R, et al. Immersive and interactive virtual reality to improve learning and retention of neuroanatomy in medical students: a randomized controlled study. CMAJ Open 2018;6:E103-E109.

7 Evans L, Taubert M. State of the science: the doll is dead: simulation in palliative care education. BMJ Support Palliat Care 2019;9:117-9.

8. Perna-Forrest L. Unlocking the potential of virtual reality in palliative care. BMJ Support Palliat Care 2017;7.

9. AmiPal Podcast, 2016. Nwosu a virtual reality and palliative care-episode 18. Available: https://www.stitcher.com/podcast/ mypal-technology-innovation-palliative-care/e/42572244 [Accessed Jan 2019].

10. Taubert M, Harvey M. Nausea and Vomiting - Student Education [YouTube]. Velindre cancer centre 2018. Available: https://www.youtube.com/watch?time_continue $=1 \& \mathrm{v}=$ F3DEnWvF4Lk [Accessed 14 Feb 2019].

11. Hill S, Patel M, Taubert M, et al. A Virtual Reality Tour Of Velindre Cancer Centre's Radiotherapy Department [YouTube]. Velindre cancer centre 2017. Available: https://www.youtube. com/watch?v=7WwNvXjVHQ8 [Accessed 04 Feb 2019].

12 Harvey M, Taubert M. When we used virtual reality cameras to create content for healthcare environments. BMJ supportive and palliative care Blog. BMJ group, 2018. Available: https:// blogs.bmj.com/spcare/2018/10/05/when-we-used-virtualreality-cameras-to-create-content-for-healthcare-environments/ [Accessed Jan 2019].

13. McCarthy B, Cleves A. We are the first health library in Wales (UK? world?) to offer VR lectures as a routine service to students and staff [Twitter]. Velindre cancer centre cancer library Twitter account 2018. Available: https://witter.com/ VCCLibrary/status/989790478160859136 [Accessed 04 Feb 2019]. 